\title{
Crossing borders to bind proteins-a new concept in protein recognition based on the conjugation of small organic molecules or short peptides to polypeptides from a designed set
}

\author{
Lars Baltzer
}

Received: 18 January 2011 /Revised: 10 March 2011 / Accepted: 12 March 2011 /Published online: 2 April 2011

(C) The Author(s) 2011. This article is published with open access at Springerlink.com

\begin{abstract}
A new concept for protein recognition and binding is highlighted. The conjugation of small organic molecules or short peptides to polypeptides from a designed set provides binder molecules that bind proteins with high affinities, and with selectivities that are equal to those of antibodies. The small organic molecules or peptides need to bind the protein targets but only with modest affinities and selectivities, because conjugation to the polypeptides results in molecules with dramatically improved binder performance. The polypeptides are selected from a set of only sixteen sequences designed to bind, in principle, any protein. The small number of polypeptides used to prepare high-affinity binders contrasts sharply with the huge libraries used in binder technologies based on selection or immunization. Also, unlike antibodies and engineered proteins, the polypeptides have unordered three-dimensional structures and adapt to the proteins to which they bind. Binder molecules for the C-reactive protein, human carbonic anhydrase II, acetylcholine esterase, thymidine kinase 1, phosphorylated proteins, the D-dimer, and a number of antibodies are used as examples to demonstrate that affinities are achieved that are higher than those of the small molecules or peptides by as much as four orders of magnitude. Evaluation by pull-down experiments and ELISAbased tests in human serum show selectivities to be equal to those of antibodies. Small organic molecules and peptides are readily available from pools of endogenous ligands, enzyme substrates, inhibitors or products, from screened small molecule libraries, from phage display, and from mRNA
\end{abstract}

\section{Baltzer $(\bowtie)$}

Department of Biochemistry and Organic Chemistry,

Uppsala University,

BMC Box 576, 75122 Uppsala, Sweden

e-mail: Lars.Baltzer@biorg.uu.se display. The technology is an alternative to established binder concepts for applications in drug development, diagnostics, medical imaging, and protein separation.

Keywords Binder technology $\cdot$ Protein $\cdot$ Molecular recognition · Polypeptide $\cdot$ Affinity $\cdot$ Specificity $\cdot$ Diagnostics

\section{Introduction}

The recognition and binding of proteins is the most critical molecular event in drug action, in diagnostics in vitro and in vivo, in industrial purification of therapeutic proteins, and in innumerable bioanalytical research applications in biotechnology and biomedicine. High affinity and specificity ensures good efficacy and minimal side effects of pharmaceuticals, and reliable identification and quantification of expression levels of biomarkers in diagnostic applications. Understanding systems biology and the search for new biomarkers in proteomics depend on multiplexed detection formats in which large numbers of proteins are captured on chip by the corresponding numbers of specific high-affinity recognition elements. The applications for molecules that bind proteins keep expanding, and issues of affinity, specificity, robustness, and time for development are in focus. New binder concepts are of greater interest than ever in drug development, in in vitro diagnostics, and in medical imaging.

Current binder technologies can, somewhat surprisingly, be grouped into two categories. They are either biological in origin or are small organic molecules prepared by synthesis. Antibodies remain the golden standard of diagnostics [1] and have in recent years become the most important new class of pharmaceutical molecules [2]. Well established procedures for development, production, and use remain strong points of antibody technologies in life 
science, and the so called humanization of antibodies [3] forms the basis for therapeutic applications by reducing immunogenicity. Insufficient specificity (cross-reactivity), interference phenomena and poor robustness remain weak points. New developments include single-chain antibodies [4] that are smaller and, in general, more robust than monoclonal antibodies. To partially overcome the weaknesses of the antibody technology phage display techniques have been employed in the engineering of proteins for binder applications. Examples include DARPins or ankyrin repeats [5], affibody molecules derived from protein A [6], and lipocalins [7]. These binders are all prepared by protein expression and identified by selection rather than design, they are robust and capable of high affinities and selectivities. The building blocks are the common amino acids. Nucleic acids are also used in protein recognition. Aptamers are polynucleic acids selected from large pools of binder candidates [8]. A frequently used argument in favour of selection methods is that huge libraries of candidates can be searched efficiently and that this feature makes it more likely to find good binders. In these technologies a single unique sequence with a well-defined fold is required to recognize a target protein.

Small organic molecules prepared by organic synthesis still form the bulk of pharmaceuticals in the clinic. Their molecular weights are low in comparison with proteins, the well-known Lipinski's rule of five state that the molecular weight of an organic molecule should be $500 \mathrm{D}$ or less in combination with a high level of lipophilicity $(\log P=5)$ to show acceptable bioavailability [9]. Organic synthesis minimizes batch to batch variations and eliminates risk of contamination from biological sources but the efforts needed to reach affinities and selectivities required for the recognition and binding of proteins in biological samples or in vivo are considerable. The costs involved in the development of small organic high-affinity molecules for efficient protein recognition can only be justified in pharmaceutical applications, and small organic molecules have had little impact in the field of diagnostics. In pharmaceutical applications the penalties are severe, because $93-97 \%$ of all drug projects are cancelled never to reach the clinic, often at a late stage of development. The reasons are most often unexpected toxicity or poor efficacy.

The growing need for specific high-affinity protein binders in life science drives the search for new molecular concepts and technologies. The search is beginning to expand beyond small organic molecules and monoclonal antibodies to include also macrocycles and peptides [10, 11]. Peptide-protein interactions are common in the control and modulation of cellular function, intercellular communication, immune responses, and signal transduction. The design of agonists and antagonists based, for example, on the introduction of conformational constraints, and back- bone and side-chain modifications in peptides, is today an established drug-development strategy.

This review covers a new synthetic strategy for molecular recognition of proteins based on the conjugation of small organic molecules or peptides to designed polypeptides $[12,13]$. The main strengths of the concept are that a small set of polypeptides can be used to develop binder molecules for any protein by conjugation to small molecules or peptides with only modest binding capacities, and that the binder molecules target the proteins that the small molecules recognise but with much improved affinity and selectivity. The review does not cover small molecules conjugated to polypeptides specifically prepared to recognize a given protein, because this approach is best described as a form of fragment-based design, and is less general. The binder technology combines the properties of biomolecules with those of small organic molecules. In the following text, in the interest of clarity, the term "binder molecule" exclusively refers to a designed polypeptide conjugated to a small organic molecule or short peptide, typically via a spacer. A "ligand" is a small organic molecule or peptide that binds to a protein and used to form binder molecules, whereas a "binder" is any molecule that binds to a protein.

\section{The polypeptide conjugate binder concept}

According to this concept a fully assembled binder molecule consists of a small organic molecule or peptide that is linked with or without an interconnecting spacer to a 42-residue polypeptide selected from a set of only sixteen sequences (Fig. 1) [12]. The small molecule must bind to the protein but only modest affinity is required. Conjugation to the polypeptide provides an assembled binder molecule that binds the protein with an affinity that is as much as four orders of magnitude higher than that of the small molecule and with increased selectivity [14]. The small organic molecule or peptide used as ligand, binds to its binding site, and the attached polypeptide finds and occupies the most favourable site of interaction on the protein surface in close proximity to the binding site of the small molecule [15]. In contrast with antibodies it is not preorganized to recognize a specific epitope but adapts and binds to the protein surface within the area that can be reached by the spacer. The polypeptide is unordered and proteins are often plastic with amino acid residues that flip and change conformation in the bound state. The bound conformation can therefore not at this stage be predicted with any accuracy from modelling. Therefore the technology is designed to enable rapid assembly and screening and the time for binder development is, by comparison, short.

The key to the binder concept is the design and function of the polypeptides that form the universal set of sixteen 
Fig. 1 Binder molecule concept illustrated for human carbonic anhydrase II (HCAII). Benzenesulfonamide is a small molecule inhibitor known to bind HCAII with a $K_{\mathrm{d}}$ of $1.5 \mu \mathrm{mol} \mathrm{L}{ }^{-1}$.

Numerous crystal structures are available to show that the sulfonamide group coordinates to the active site $\mathrm{Zn}^{2+}$ ion at the bottom of a $10 \AA$ deep pocket. From the available structural information it was assumed that an aminohexanoic acid spacer would provide sufficient distance from the active site to the protein surface to enable the polypeptide to fold and bind cooperatively with the benzenesulfonamide group. The aminohexanoic acid spacer was incorporated by organic synthesis and the active ester was reacted with each member of the set of polypeptides to form the candidate binder molecules. Evaluation by fluorescence titration, indicated by the coumarin fluorophore, identified highaffinity binders. PDB ID: 1CA2
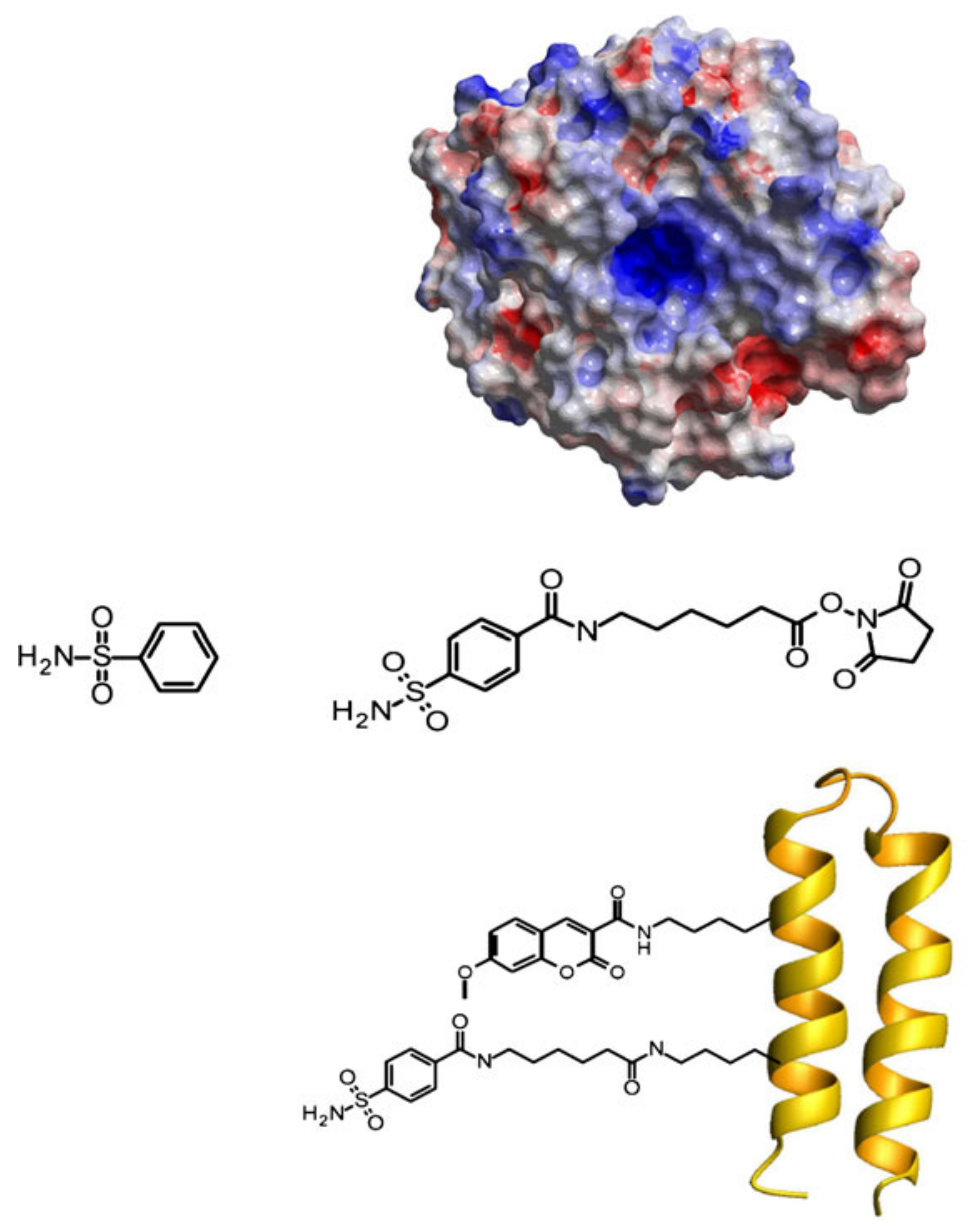

sequences, a number that is very small in comparison to the large libraries used in binder development based on immunization or selection (Fig. 2). The main reason that only sixteen sequences are needed to develop binders for, in principle, hundreds of thousands of proteins is that the contribution of the polypeptide to the overall binding is relatively small. By design, the polypeptides are given the capacity to present many potentially interacting groups to the target protein surface and it is only necessary for a few of those to engage in productive binding to raise the affinity 1000-fold, for example. In order for the assembled binder molecule to have a dissociation constant that is three orders of magnitude lower than that of the small molecule ligand, the polypeptide needs to contribute less than $20 \mathrm{~kJ} \mathrm{~mol}^{-1}$ of binding energy at room temperature [16]. That amount of binding energy corresponds to a few hydrophobic contacts between 2 or 3 leucine residue side chains from the polypeptide and hydrophobic groups presented by the protein, or a few hydrophobic contacts in combination with charge-charge interactions and hydrogen bonding. The polypeptides were given some propensity for forming amphiphilic helices with two helices linked by a short loop $[17,18]$ and the design is based on two structural variables. There are four different combinations of charged residues and four different positions of attachment of the small molecule ligand, altogether sixteen combinations and thus sixteen sequences (Fig. 2) [12] The hydrophobic residues are the same throughout the set and the charged residues are introduced along the perimeter of the hydrophobic faces of the amphiphilic helices to bring them into close proximity to protein surface residues. Although the polypeptide itself is a weak binder, it is covalently linked to the small molecule which binds to the protein, and the entropic penalty associated with the polypeptide-protein interaction has therefore been eliminated or, at least, drastically reduced [16]. Because only a few interactions are required between polypeptide and protein, only a few amino acid residues have to be involved in binding to a given protein, and a polypeptide of 42 amino acid residues represents a large number of combinations of amino acid side chains capable of providing the necessary binding energy. The capacity to bind to a variety of potential binding sites on the surfaces of many proteins is thus embedded in the polypeptide construct.

The polypeptides were designed to supplement the binding energy provided by the small molecule ligand predominantly by hydrophobic interactions. Charged residues were introduced in positions next to the hydrophobic ones to increase selectivity due to charge-charge interac- 
Fig. 2 The set of sixteen polypeptide sequences used to develop binder molecules by conjugation to small organic molecules or peptides. Aspartic and glutamic acids are colourcoded red, whereas arginines are blue, to illustrate the systematic variation of charged residues. The sites of incorporation of fluorophores and small molecule ligands are shown in bold italics and underscored and are evident from the sequence name. 1-C15L8 has a coumarin fluorophore at the side chain of Lys 15 and a small molecule ligand at the side chain of Lys8, etc. All amino terminals are acetylated whereas carboxy terminals are amidated in some sequences and free in others

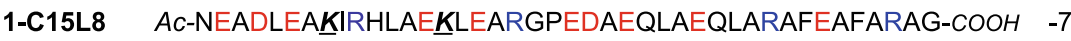 \\ 2-C15L8 Ac-NEADLEAKIRHLAEKLAARGPVDAAQLAEQLARAFEAFARAG-COOH -4 \\ 3-C15L8 Ac-NAADLEA $\underline{K}$ IRHLAEKLAARGPVDAAQLAEQLARRFEAFARAG-CONH $\mathrm{H}_{2}-1$ \\ 4-C15L8 Ac-NAADLEA $\underline{K}$ IRHLREKLAARGPRDAAQLAEQLARRFERFARAG-CONH ${ }_{2} \quad+2$ \\ 1-C10L17 Ac-NAADLEAAIKHLAEALKERGPEDCEQLAEQLARAFEAFARAG-COOH $\quad-7$ \\ 2-C10L17 Ac-NAADLEAAIKHLAEALKARGPVDAAQLAEQLARAFEAFARAG- $\mathrm{COOH} \quad-4$ \\ 3-C10L17 Ac-NAADLEARIKHLAERLKARGPVDAAQLAEQLARAFEAFARAG-CONH \\ 4-C10L17 Ac-NAADLEARIKHLRERLKARGPRDAAQLAEQLARAFERFARAG-CONH $\mathrm{H}_{2}+2$ \\ 1-C25L22 Ac-NEADLEAAIRHLAEALEARGPKDAKQLAEQLARAFEAFERAG-COOH -6 \\ 2-C25L22 Ac-NEADLEAAIRHLAEALAARGPKDAKQLAEQLARAFEAFARAG-COOH $\quad-4$ \\ 3-C25L22 Ac-NAADLEAAIRHLAERLAARGPKDAKQLAEQLARAFEAFARAG-CONH $\mathrm{N}_{2} \quad-1$ \\ 4-C25L22 Ac-NAADLEARIRHLRERLAARGPKDAKQLAEQLARAFERFARAG-CONH ${ }_{2}+2$ \\ 1-C37L34 Ac-NEADLEAAIRHLAERLEARGPADAAQLAEQLAAKFEKFARAG- $\mathrm{COOH} \quad-5$ \\ 2-C37L34 Ac-NAADLEAAIRHLAERLAARGPVDAAQLAEQLAAKFEKFARAG- $\mathrm{COOH} \quad-3$ \\ 3-C37L34 Ac-NAADLEAAIRHLAERLAARGPVDAAQLAEQLARKFEKFARAG-CONH $\mathrm{H}_{2}-1$ \\ 4-C37L34 Ac-NAADLEARIRHLRERLAARGPRDAAQLAEQLARKFEKFARAG-CONH ${ }_{2}+2$
}

tions between residues in the polypeptides and those on the protein surface. A helical conformation was expected to improve the presentation of the hydrophobic residues and in the helical conformation the charged amino acid residues introduced next to the hydrophobic ones are forced in contact with the residues on the protein surface to enhance selectivity (Fig. 3). In solution the polypeptides form helixloop-helix motifs that dimerise to form four helix bundles at micromolar concentrations but dissociate to unordered

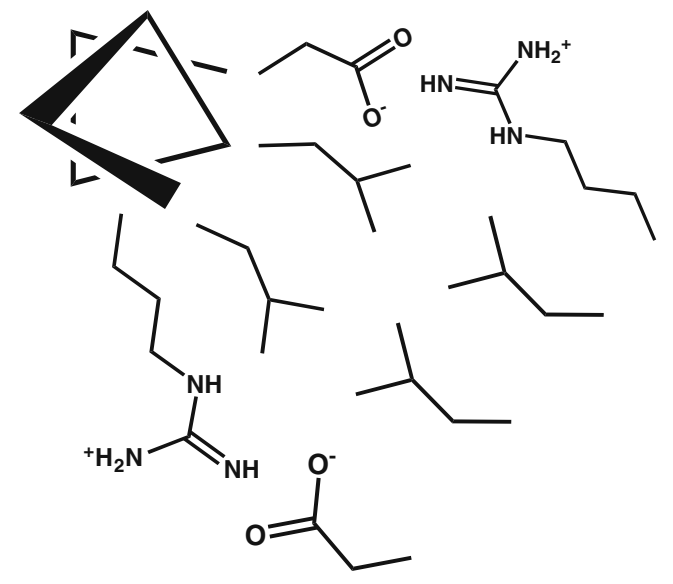

Fig. 3 Schematic illustration of principle behind design of helical propensity in polypeptide sequences. The amphiphilic helices have hydrophobic residues in positions that are flanked by charged residues. Hydrophobic residues in the polypeptide sequences are expected to interact with hydrophobic residues exposed on the protein monomers at nanomolar concentrations [12, 17]. Their NMR spectra show the hallmarks of molten globules and they melt uncooperatively. The concept is more closely related to so called intrinsically disordered proteins [19], proteins that fold productively only in contact with their targets, than to antibodies or engineered proteins. As a consequence of the small size the binders do not denature, and they can be stored in the lyophilized state without loss of activity. They are extremely robust and suitable for

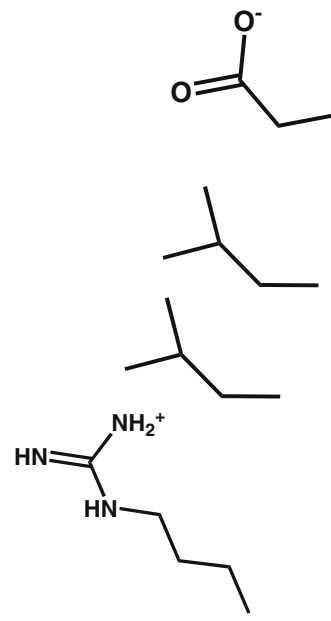

surface. In a helical conformation the charged flanking residues are forced in contact with residues on the protein surface. If charged residues are forced in contact with residues of the opposite charge the polypeptide will bind, left panel. If not, binding will be very weak or undetectable, right panel 
applications in which optimum storage conditions are not available or not convenient. There is, as yet, no highresolution information about the structure of the binder molecules complexed to proteins and understanding of how they actually bind remains hypothetical. Only indirect evidence from NMR and CD spectroscopy exists in support of the expectation that the polypeptides form helices and fold into hairpin motifs in the bound state [15].

The small molecules or peptides are conveniently obtained from the pool of known endogenous ligands described in the literature. A selective high-affinity binder for the C-reactive protein (CRP) was developed from phosphocholine that is known to bind CRP with a $K_{\mathrm{d}}$ of $5 \mu \mathrm{mol} \mathrm{L}{ }^{-1}$ in the presence of $\mathrm{Ca}^{2+}$ [12] and a binder for thymidine kinase 1 (TK1) was developed from deoxythymidine (Stauffiger, A., Sun, X., Virtanen, A., Baltzer, L., unpublished), a substrate for the kinase with similar affinity. The small molecule can also be identified from a search of the organic chemistry literature. Proteins that have reached the status of biomarkers have frequently been well investigated and the literature is rich in small organic molecules designed to bind important biomarkers, but with affinities and selectivities insufficient for biomedical applications. They are excellent starting points for the development of binder molecules. When small molecule ligands for proteins are not available they can be identified from selected libraries by spectroscopic methods. There are today well established NMR spectroscopy experiments designed for this particular purpose based on the effects that binding of small molecules have on chemical shifts or relaxation $[20,21]$. The search for small molecules that bind poorly characterized proteins may seem like a cumbersome and tedious approach but the identification of moderately tight binders for proteins is far less ambitious than the development of tight binders. Peptides that bind proteins are identified from the peptide epitopes of native protein ligands if the target protein is involved in proteinprotein interactions or from phage display or m-RNA display $[22,23]$. Again, the peptides that bind proteins need not bind with high affinities, because polypeptide conjugation enhances binder performance.

A binder molecule for the D-dimer protein with a $K_{\mathrm{d}}$ of $2 \mathrm{nmol} \mathrm{L} \mathrm{L}^{-1}$ was obtained by conjugating the GPRP tetrapeptide, that binds the D-dimer with $25 \mu \mathrm{mol} \mathrm{L}{ }^{-1}$ affinity, to the polypeptide scaffold 4-C15L8 (Fig. 4) [24]. The ratelimiting step in the development of binder molecules based on small organic compounds is the organic synthesis required to modify the small molecule ligand. The introduction of a spacer carrying functional groups for conjugation to the polypeptide, for example $p$-nitrophenyl esters, will take weeks and may even take months of organic synthesis. The conjugation of peptides is, by comparison, straightforward, because of the well advanced stage of solid-phase peptide synthesis. A limitation of the concept is that purified target protein must be available in the development process. Antibodies, in contrast, may be produced from protein sequence information.

Selection of the spacer is based on available crystal structures or trial and error. From crystal structures the required spacer length can be estimated on the basis of the distance from the small molecule binding site to the surface of the protein where the polypeptide binds. In the case of a binder molecule for human carbonic anhydrase II (HCAII), aminohexanoic acid was selected $[25,26]$. The pocket is approximately $10 \AA$ deep and the combination of benzenesulfonamide carboxylic acid with the aminohexanoic acid was expected to enable the polypeptide to dock on the surface of the protein with the sulfonamide group coordinated to the $\mathrm{Zn}^{2+}$
Fig. 4 Illustration of a binder molecule based on a short peptide fragment. GPRP binds to the D-dimer with a $K_{\mathrm{d}}$ of $25 \mu \mathrm{mol} \mathrm{L}{ }^{-1}$ in a surfaceexposed position. Conjugation to polypeptides gives a fully assembled binder molecule that binds with a $K_{\mathrm{d}}$ of $2 \mathrm{nmol} \mathrm{L}-1$. Representation of D-dimer structure from crystal structure. PDB ID:1FZB
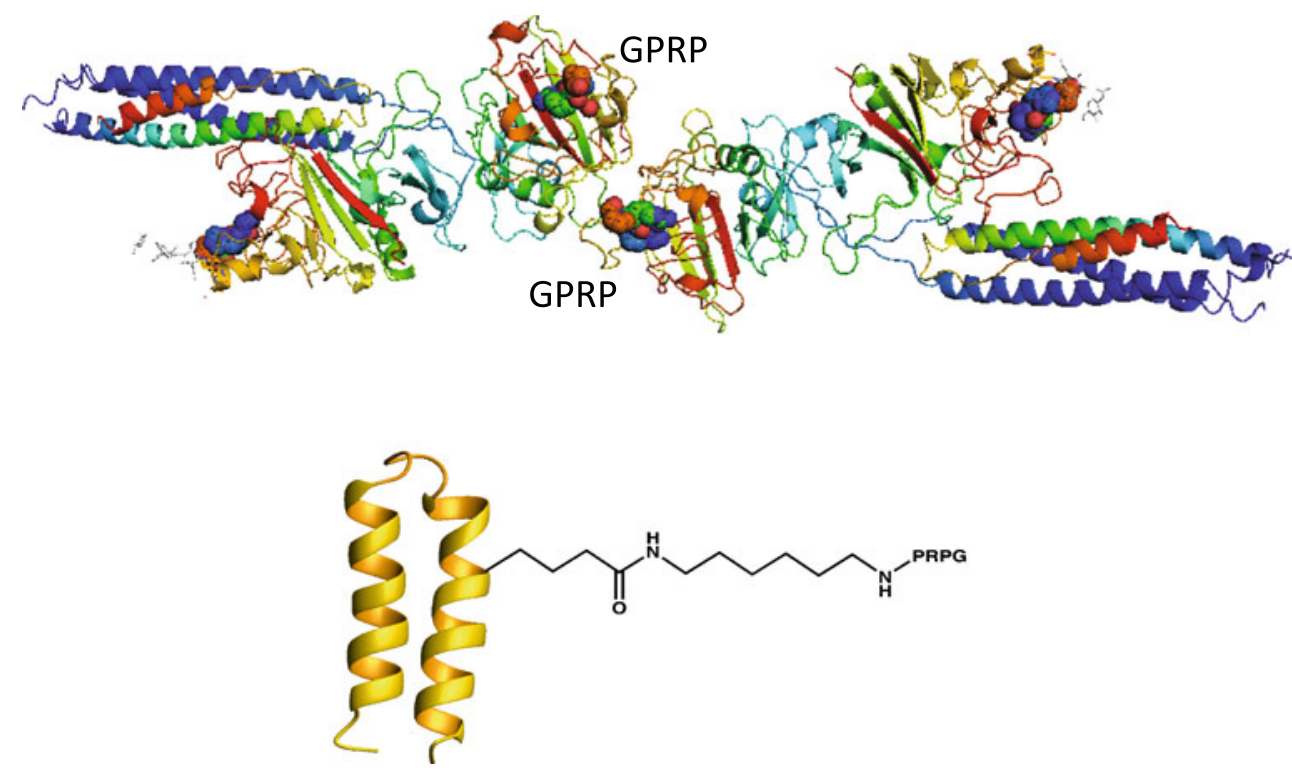
ion in the active site. The size of the spacer was critically evaluated using a set of aminocarboxylic acids with the amino and carboxylic acid groups separated by 0 to 10 methylene groups [15]. Affinities were determined by fluorescence titration and the spacers with zero, one, three, and four methylene groups had approximately the same affinity as benzenesulfonamide, with dissociation constants between 3 and $0.8 \mu \mathrm{mol} \mathrm{L}{ }^{-1}$, whereas the spacer with five methylene groups bound HCAII with a $K_{\mathrm{d}}$ of $20 \mathrm{nmol} \mathrm{L}^{-1}$ [27]. The increase in spacer length by a single methylene group was thus shown to lead to an affinity increase by a factor of 40 and a further extension by two methylene groups gave rise to a further fourfold increase in affinity. The results showed that a spacer long enough to extend out of the pocket provided enough conformational freedom for the polypeptide to fold and bind to a site on the protein surface, whereas too short a spacer prevented the polypeptide from folding and binding in the constricted space of the binding pocket. A binder for acetylcholine esterase with an active site buried in a $20 \AA$ deep pocket required a 16 atom spacer for binding (Winander, C., Tegler, L.T., Baltzer, L., unpublished). In all of the reported binder molecules aliphatic spacers were used and the PEG spacers commonly used in bioconjugation chemistry were only used for the purpose of avoiding interactions with the protein that could interfere with binding.

\section{Polypeptide conjugate binder molecules}

The most well characterized binder molecule is that which binds CRP [28]. CRP is a general inflammation marker and a component of the complement activation system. CRP is upregulated as a consequence of, for example, viral or bacterial infections and is measured routinely in hospitals. The so called high-sensitive CRP test is used as a cardiovascular risk marker [29]. The binder molecule was designed on the basis of the crystal structure of the CRP-phosphocholine complex [30] which suggested that one of the methyl groups of the phosphocholine ammonium ion could be replaced by an aliphatic spacer without loss of binding affinity. The phosphate group binds via intercalating $\mathrm{Ca}^{2+}$ ions to the side chains of aspartic acids, glutamic acids, an asparagine, and a glutamine residue. Instead of a methyl group the phosphocholine derivative was equipped with an aliphatic spacer carrying a terminal $p$-nitrophenyl ester. It was subsequently reacted with each of the sixteen members of the designed set of polypeptides to form the candidate binder molecules (Fig. 5). There is only a single free lysine in each polypeptide and the N-terminal amino groups are all acetylated to avoid incorporation of multiple ligands. Screening by fluorescence titration in microtitre plate format revealed an unusually large number of tight binders, eleven
Fig. 5 The design of the binder molecule for the C-reactive protein (CRP) was guided by inspection of the crystal structure of the CRP-phosphocholine complex. CRP is a symmetric pentamer and each of the subunits binds one phosphocholine molecule with a $K_{\mathrm{d}}$ of

$5 \mu \mathrm{mol} \mathrm{L}{ }^{-1}$. The phosphate group coordinates to aspartic and glutamic acids, and to an asparagine and a glutamine residue via a $\mathrm{Ca}^{2+}$ ion. The trimethylammonium ion, in contrast, was not involved in highly specific interactions and one of the methyl groups of phosphocholine was therefore replaced by an aliphatic spacer carrying an active ester endgroup, to enable conjugation to the free lysine residue in each of the polypeptides of the sixteenmembered set. PDB ID:1B09

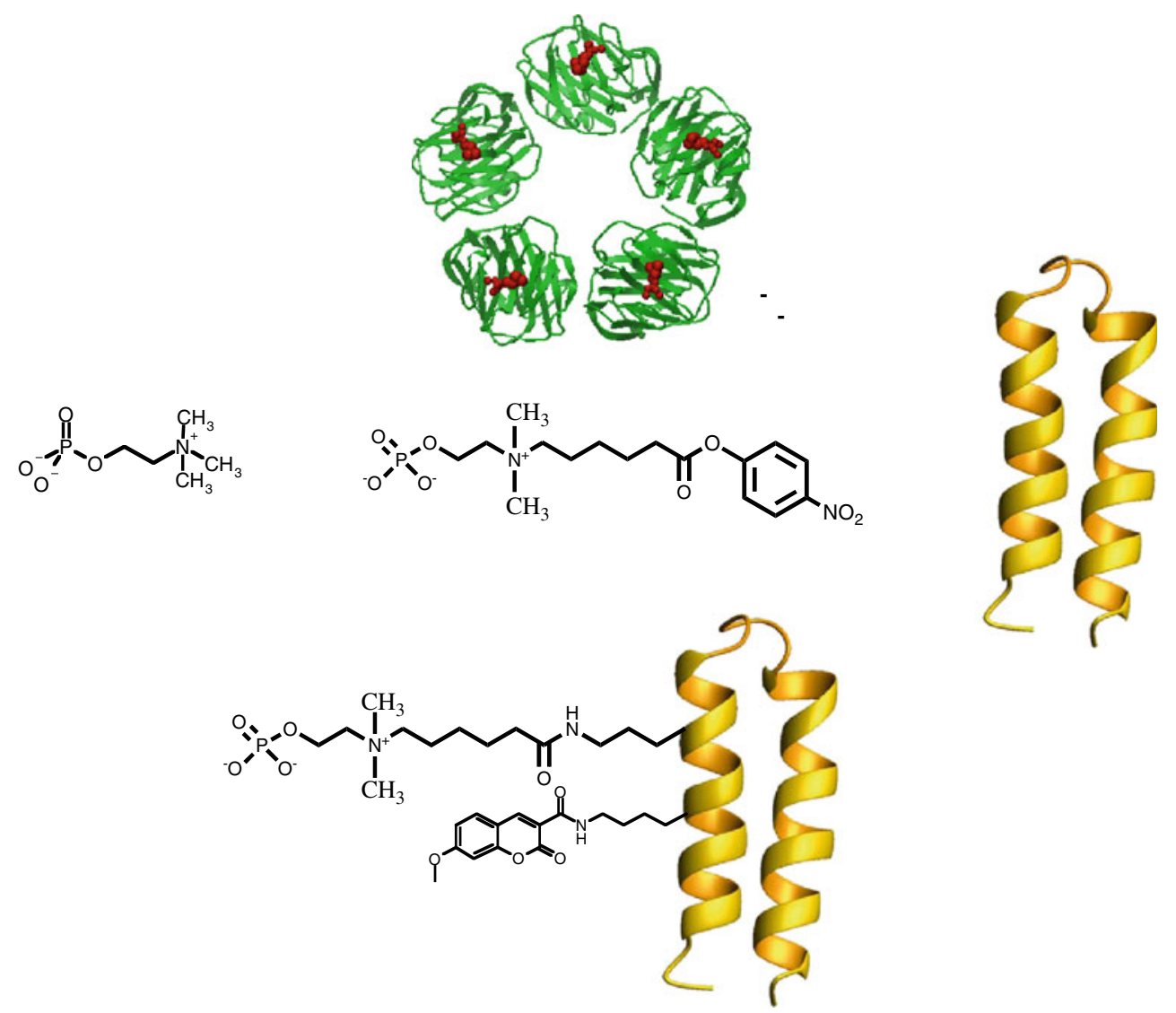


out of sixteen candidates responded in the presence of $\mathrm{CaCl}_{2}$ to the presence of CRP in a way that suggested their dissociation constants were in the low nanomolar range or lower. Evaluation by SPR biosensor analysis (Biacore) was largely in agreement with screening by fluorescence in solution, and showed that the effect on affinities was essentially because of reduced kinetic off-rates although effects on on-rates were also observed. The kinetic behaviour could not be described by single exponential functions but was more complex; no standard equations available from the commercially available software showed good correlation with the experimental data, mainly because binding did not show saturation. This issue remains unresolved as solution titrations saturate at concentrations where saturation is not observed by SPR analysis. Lack of saturation is observed also with other protein-binder complexes but only in the analysis by SPR. The binder molecules shown to have the highest affinities for CRP out of the sixteen candidates were the same, with one exception, irrespective of method, and $K_{\mathrm{d}}$ values in the high picomolar to low nanomolar range were clearly obtained by conjugating polypeptides to the phosphocholine derivative that binds CRP with a dissociation constant of $6 \mu \mathrm{mol} \mathrm{L}{ }^{-1}$ [31]. The strongest binders were found in the group with phosphocholine linked to the polypeptides 4-C37L34, 4-C10L17, and 4-C25L22, with that of 4-C10L17 being the binder molecule with highest affinity in most applications. Pull-down experiments with human serum from patient samples were used to evaluate selectivity, and binder molecules were compared with an avian antibody developed towards CRP. SDS-PAGE showed that 4-C10L17 conjugated to phosphocholine via a spacer was as selective as the antibody in human serum. Selectivity equal to that of the antibody was also observed in a variety of bioanalytical test formats including ELISA (see below).

The first example of a binder molecule based on a small organic molecule with moderate affinity for a protein conjugated to a polypeptide not specifically developed to bind the protein was reported in 2002 [25]. A 42-residue polypeptide, KE2, was linked via an aliphatic spacer to benzenesulfonamide, a known inhibitor of HCAII with a dissociation constant of $1.5 \mu \mathrm{mol} \mathrm{L}{ }^{-1}$, to form a binder molecule that bound HCAII with a dissociation constant of $5 \mathrm{nmol} \mathrm{L}{ }^{-1}$ [15]. HCAII is an enzyme that catalyzes the interconversion of bicarbonate and carbon dioxide, and is not a commonly used biomarker although it is a drug target for glaucoma [32], and there are reports to suggest that it is an emerging biomarker for cancer [33]. Recently, the detection of HCAII was reinvestigated using the set of sixteen designed polypeptides [14]. Again a strong binder was identified with a $K_{\mathrm{d}}$ of $17 \mathrm{nmol} \mathrm{L}{ }^{-1}$. The selectivity towards HCAII of the binder 4-C37L34 conjugated to benzenesulfonamide was evaluated by pull-down experiments in freshly drawn whole blood with the red blood cells lysed by the addition of distilled water. Lysis was necessary to access HCAII, since HCAII is not present in serum unless the red blood cells leak due to damage inflicted on the cell wall. Human carbonic anhydrase I (HCAI) also exists in red blood cells, at a concentration 5-7-fold higher than that of HCAII [34], but with less catalytic activity. HCAI and HCAII are $60 \%$ homologous with nearly identical molecular weights and cannot be separated by SDS-PAGE. Both isoforms bind benzenesulfonamide with essentially identical affinities; reported $K_{\mathrm{d}}$ values vary between 1.3 and $1.5 \mu \mathrm{mol} \mathrm{L} \mathrm{L}^{-1}$ for HCAII [34-36] and between 1.1 and $3.9 \mu \mathrm{mol} \mathrm{L}{ }^{-1}$ for HCAI $[35,37]$. The conjugation of benzenesulfonamide to polypeptides was expected to generate binder molecules with differences in affinity as the electrostatic profile of the protein surfaces differ, and determination of dissociation constants by SPR analysis revealed a difference in affinity by a factor of 30 [14]. The results suggest that binder molecules with increased selectivity can be obtained for difficult small molecule targets using the polypeptide conjugation technology.

These examples take advantage of an endogenous ligand and a known enzyme inhibitor. Enzyme substrates and products can also be used although it would be expected that an enzyme substrate undergoes a chemical transformation and become modified whereas a product of an enzymecatalyzed reaction should be expelled. Thymidine kinase catalyses the phosphorylation of deoxythymidine to form the corresponding nucleotide, and thymidine kinase 1 (TK1) is a biomarker for cancer [38]. Conjugation of deoxythymidine to the polypeptides gave rise to several binder molecules with low nanomolar affinities (Stauffiger, A., Sun, X., Virtanen, A., Baltzer, L., unpublished). In the presence of ATP, to mimic the detection of TK1 in serum, the binder molecule was phosphorylated, as demonstrated by MALDI-TOF mass spectrometry. Surprisingly both the substrate-based and product-based binder molecules have very high affinity for TK1, in the low nanomolar range or better according to fluorescence titration. The reason that phosphorylated deoxythymidine conjugated to a polypeptide bound strongly to the enzyme is the considerable increase in affinity of the assembled binder in comparison with the phosphorylated substrate, the reaction product.

Peptides are excellent ligands for binder development. The tetrapeptide GPRP has been shown to bind to the D-dimer protein, a well known biomarker for thrombosis [39], with $25 \mu \mathrm{mol} \mathrm{L}^{-1}$ affinity [24]. The conjugate formed by attaching GPRP to 4-C15L8 via a six-carbon spacer bound the D-dimer with $3 \mathrm{nmol} \mathrm{L}^{-1}$ affinity, an increase by four orders of magnitude over that of the tetrapeptide [40]. GPRP was shown to completely inhibit binding, and that the conjugate binds exclusively and specifically to the GPRP binding site. The D-dimer is a degradation product from fibrinogen and arises as a result of the formation of 
blood clots. It is a biomarker of great diagnostic value in the clinic.

The recognition of antibodies is conveniently carried out by conjugating epitopes recognized by the antibody to a polypeptide followed by immobilization of the binder molecule in the wells of a microtitre plate and an ELISA using commercially available anti-antibody antibodies for detection. Alternative methods include the direct immobilization of the epitope or the immobilization of streptavidine followed by capture of the biotinylated epitope. The use of the synthetic peptide-polypeptide conjugate was shown to give better reproducibility than alternative methods, probably because of increased affinities and improved presentation of the peptide antigen (Fromell, $\mathrm{K}$ and Baltzer, L. unpublished).

A consequence of the binder molecule concept is that if the small molecule ligand recognises not a specific epitope or binding site of a given protein but a specific group found in proteins, for example as a result of post-translational modification, then binders for groups of proteins can be developed. Phosphorylation is the most commonly occurring posttranslational modification [41] and a small molecule binder for phosphate was linked to the polypeptides in the search for binder molecules for groups of phosphorylated proteins, possibly all [42]. The small molecule ligand complexes two $\mathrm{Zn}^{2+}$ ions and binds phosphate ions with dissociation constants reported to be in the range from 28 to $640 \mu \mathrm{mol} \mathrm{L}{ }^{-1}$ [43]. The small molecule ligand was conjugated to the side chain of a lysine residue in eight of the polypeptides without connecting linker, because the objective was to bind phosphoserines and phosphothreonines that do not extend far from the protein surface (Fig. 6). The binder molecule for phosphorylated proteins formed by conjugation to the polypeptide 4-C15L8 of the small molecule

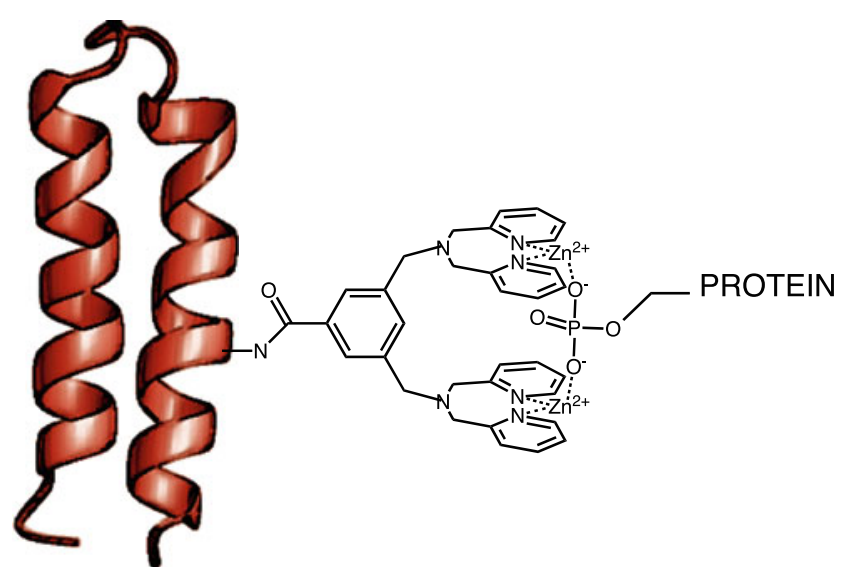

Fig. 6 Binder concept for recognition of proteins phosphorylated at side-chains of serine and threonine residues. Small molecule binds two $\mathrm{Zn}^{2+}$ ions in fixed geometry that binds phosphate ions. Phosphoserines and phosphothreonines do not extend far out from the protein surface so no spacer was introduced ligand followed by $\mathrm{Zn}$ complexation, binds the model protein $\alpha$-casein with a $K_{\mathrm{d}}$ of $17 \mathrm{nmol} \mathrm{L}{ }^{-1}$, extracts $\alpha$-casein from a $10 \mathrm{nmol} \mathrm{L}^{-1}$ solution, is not replaced by a 10,000 -fold excess of phosphate ions, and extracts $\alpha$-casein specifically from spiked human serum [42]. The same binder molecule binds $\beta$-casein and the phosphorylated proteins Erk1 and Erk2, but not Akt1 and ovoalbumin. The concept is being extended to the detection of large groups of phosphorylated proteins by combination of a number of binder molecules from the candidate set. The binder molecule was also immobilized on polystyrene beads and used to capture $\alpha$-casein under flow on a column (Slosarczyk, A., Baltzer, L. unpublished). The captured $\alpha$-casein was released by $0.1 \%$ formic acid and identified in the eluate by mass spectrometry. An interesting application is the use of columns developed for capture of post-translational modified proteins in combination with mass spectrometry or SDS-PAGE.

\section{Applications}

Antibodies are the golden standard of bioanalytical assays with experimental procedures developed to a level where antibodybased ELISAs and pull down experiments are used routinely also in non-specialist laboratories. For comparison, the binder molecules reviewed here have been included in standard bioanalytical test formats and compared with antibodies. The binder molecule for CRP was used as capturing agent in an ELISA used to detect CRP from patient sera with HRP conjugated antibodies used for detection [12]. The doseresponse curve was comparable with that obtained using a commercially available antibody-based sandwich. The CRP binder molecule was also used in a pull-down experiment followed by detection with SDS-PAGE. The protein bands extracted by the binder molecule from patient serum with upregulated CRP levels were essentially identical to those extracted by an avian antibody to CRP. While antibodies are typically immobilized simply by incubation and non-covalent attachment to hydrophobic surfaces such as polystyrene, the synthetic binder molecules were immobilized using Pluronics molecules that form self-assembled PEG monolayers carrying activated disulfide end groups and react spontaneously in an exchange reaction to form disulfide bonds with unprotected thiols. The Pluronics molecule has a polypropyleneoxide base which is highly hydrophobic, and two PEG arms with pyridylsulfide (PDS) groups coupled to the terminal thiols [44]. CRP binder molecules equipped with unprotected Cys residues in the loop region were linked to Pluronics molecules immobilized on the surface of polystyrene beads and in the wells of polystyrene microtitre plates. This setup provided results in pull down experiments and ELISAs that were comparable with those based on antibodies with regard to specificity and level of non-specific binding. In contrast, 
the immobilization of binder molecules on a diamond surface using the Pluronics technology provided a test format with excellent performance and much beyond that shown by antibodies in standard formats with regard to suppression of non-specific binding [45]. The signal-to-noise ratio obtained was unprecedented for low concentrations of CRP. While diamond surfaces will remain at the research stage for some time and is not likely to reach research laboratories soon, the excellent performance of diamond surfaces coated with Pluronics suggest that advances in materials science can be used to dramatically improve current test formats.

Nitrocellulose membranes are well established and inexpensive bioanalytical test platforms. Immobilization of capturing molecules on nitrocellulose is achieved by baking at high temperature, typically $70{ }^{\circ} \mathrm{C}$ or above. The functional membrane allows all biomolecules that are not specifically recognized by the capturing element to pass through to an adsorbent fixed under the membrane, while retaining the target molecules for detection. Current detection methods include the addition of binders, most often antibodies, conjugated to gold nanoparticles followed by quantitative measurement of the red colour by spectroscopic methods. The CRP binder molecule 4-C10L17-PC6 was immobilized on nitrocellulose by baking at $100{ }^{\circ} \mathrm{C}$ for $12 \mathrm{~h}$. CRP from serum was captured without detectable leakage demonstrating that the performance of the binder was equal to that of the antibody of the commercially available test [46].

A test format somewhat more ingenious in nature was developed on the basis of two binder molecules, one that selfassociated in the presence of $\mathrm{Zn}^{2+}$ ions and one that bound HCAII [47]. The binder molecules were co-immobilized on gold nanoparticles and in the presence of $\mathrm{ZnCl}_{2}$ the gold nanoparticles aggregated to give an intense violet colour because of the gold nanoparticle resonance phenomenon. After addition of HCAII the nanoparticles were forced apart by the bulkiness of the protein, resulting in a clearly visible change of colour to red. This test format is useful for the detection of proteins, but not for quantification, because the colour transition takes place over a narrow concentration range.

The development of chip-based technologies using nonsandwich detection formats are of considerable interest, because of the reduced complexity and shortened measurement time. In addition, the increased information content, including, for example, binding kinetics, obtained from modern measurement devices suggests they will be the standard platforms in point of care applications very soon. Optical chip-based technologies based on change in refractive index and layer thickness provide better results the smaller the recognition element. Reflectometric interference spectroscopy (RifS) [48] is an optical detection method based on interference between light beams reflected at the interfaces of a slide coated with recognition elements as a function of binding. The technology is robust and does not depend on sophisticated chip technology for analysis-simple glass slides are sufficient. Two CRP binder molecules were covalently immobilized on glass chips and evaluated by RifS for the purpose of detecting CRP in human serum. The binder technology is an excellent alternative to antibodies in chip-based detection formats as it provides an opportunity to implement large ranges of detection because of to the wide range of affinities that is obtained in the screening procedure [49].

Polypeptide conjugate binder technology thus shows great promise as provider of recognition elements to be applied in modern bioanalytical measurement formats. The binder molecules are robust and prepared by synthesis, they are easy to modify site-specifically, and a range of affinities is obtained as a consequence of the variation in affinity enhancement provided by the polypeptides. The incorporation of functional groups for immobilization or for linkage to fluorophores, nanoparticles, radiolabels, etc., is well controlled.

\section{Binder molecule development}

An important aspect of any binder technology is the effort required to develop binders for specific proteins, equipped for given applications, and what skills are required. The rate-limiting step in the preparation of synthetic binder molecules is the synthesis of the small molecule ligand or peptide equipped with spacers and functional groups for polypeptide conjugation, e.g. spacers with $p$-nitrophenyl ester end groups. The synthesis of the $p$-nitrophenyl ester of phosphocholine required seven steps of intermediate difficulty [12]. The synthesis of the small molecule ligand for HCAII equipped with a spacer and an active ester was, by comparison, simple and required only three steps, because the carboxylic acid of benzenesulfonamide is commercially available [25]. An extreme example was the synthesis of the ligand for the vitamin $\mathrm{D}$ binding protein, which required 23 steps, and a synthesis to be attempted only by highly experienced synthetic organic chemists [50]. Consequently, binder molecule development depends to a large extent on the small molecule binders that are available and known to bind to the target. The development of binder molecules based on small molecules depend primarily on experience in organic synthesis whereas the development of binder molecules based on peptides depend on peptide synthesis and are by comparison straightforward to prepare.

The preliminary evaluation or screening of binder performance is carried out in microtitre plate format, by addition of solutions containing $500 \mathrm{nmol} \mathrm{L}^{-1}$ binder molecule equipped with a fluorophore, for example dansyl or coumarin, to wells coated to avoid non-specific binding [12]. The binder molecules are small and passivation by BSA, the standard for antibody-based tests, is not sufficient 
to avoid non-specific binding. Pluronics are conveniently used to coat surfaces but home-made "sticky" peptides may serve as alternatives. In test formats where the binder molecules are covalently linked to the surface and not free in solution, special passivation is not required.

The addition of protein in $500 \mathrm{nmol} \mathrm{L}^{-1}, 1,000 \mathrm{nmol} \mathrm{L}^{-1}$, and $1,500 \mathrm{nmol} \mathrm{L}^{-1}$ concentrations to wells containing $500 \mathrm{nmol} \mathrm{L}^{-1}$ binder molecule followed by the measurement of fluorescence intensity enables simple and rapid estimation of affinity (Fig. 7). If the fluorescence is affected by the addition of protein, binding has been established. If the fluorescence intensity does not increase or decrease further upon addition of more protein, then binding has been saturated at binder and protein concentrations of $500 \mathrm{nmol} \mathrm{L}^{-1}$. Assuming an experimental uncertainty of $10 \%$ the concentration of the complex is $450 \mathrm{nmol} \mathrm{L}^{-1}$ and the concentration of the free binder and free protein is $50 \mathrm{nmol} \mathrm{L}^{-1}$. From these concentrations a dissociation constant of $5 \mathrm{nmol} \mathrm{L}^{-1}$ can be estimated, which is the dissociation constant of a high-affinity binder. The estimate is, of course, approximate but the screening procedure and the identification of highaffinity binder molecules from the fluorescence based assay are rapid and efficient.

Further evaluation of "hits" is carried out by SPR biosensor analysis, by more accurate fluorescence titrations, by ELISA, and by pull down experiments, with a focus on accurate dissociation constants and selectivity in serum or blood.

\section{Robustness, serum, and chemical stability}

Unfolding and aggregation of proteins, or denaturation, does not in general occur with polypeptides with unordered conformations. Unlike antibodies the binder molecules that are 42-residue polypeptide conjugates can be heated and cooled to room temperature without loss of function [17]. The effect of temperature on the helical signature of the polypeptides was shown to be reversible by $\mathrm{CD}$ spectroscopy. High temperature or storage at room temperature therefore does not degrade the performance of the binder molecules. Degradation of peptides by proteolytic enzymes is known to occur rapidly in vivo. Human serum contains proteolytic enzymes and incubation in serum will cause partial degradation of peptides and proteins, although folded proteins are more resistant to enzymatic degradation. The problem is much more pronounced with in vivo applications. Artificial amino acids and side-chain modifications of common amino acids increase lifetimes of peptides because they are not recognized by native enzymes and, therefore, not hydrolyzed. Incorporation of organic substituents at the side chains of lysine residues was shown to increase the lifetime of the polypeptide decorated with two substituents (Ramapanicker, R. unpublished). Non-natural amino acids also protect neighbouring amide bonds from hydrolysis and the level of protection from proteolysis required can be further controlled by incorporation of non-degradable amino acids, for example $\beta$-amino acids [51] or D-amino acids. The polypeptide 4-C15L8 was completely degraded in less than an hour but incorporation of a phosphocholine group in position 8 and a dansyl group in position 5 , reduced degradation in human serum at $37^{\circ} \mathrm{C}$ to approximately $20 \%$ in two hours, and further incorporation of a substituent in the loop region formed a polypeptide conjugate for which no degradation was observed after five hours in human serum at $37^{\circ} \mathrm{C}$ (Ramapanicker, R. unpublished). Incorporation of organic groups at the side-chains of amino acid residues in polypeptides therefore extends the lifetimes in serum to levels that can be tuned by adjusting the number of substituents or unnatural amino acids that are incorporated.

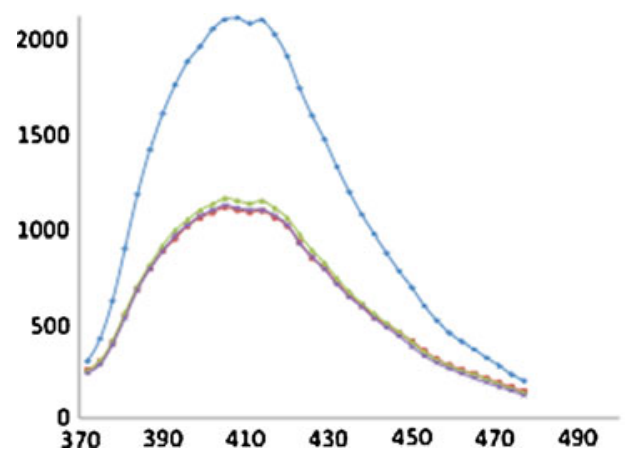

Fig. 7 Illustration of fluorescence titration for identification of tight binders in rapid screening procedure. Left panel shows a "hit" because the fluorescence emission spectrum of $500 \mathrm{nmol} \mathrm{L}^{-1}$ of binder molecule (blue trace) is affected by addition of $500 \mathrm{nmol} \mathrm{L}^{-1}$, $1,000 \mathrm{nmol} \mathrm{L}{ }^{-1}$ and $1,500 \mathrm{nmol} \mathrm{L}^{-1}$ protein (green, red, and violet traces), and therefore binds to the protein. Because there is no further change in the fluorescence spectrum after addition of one equivalent

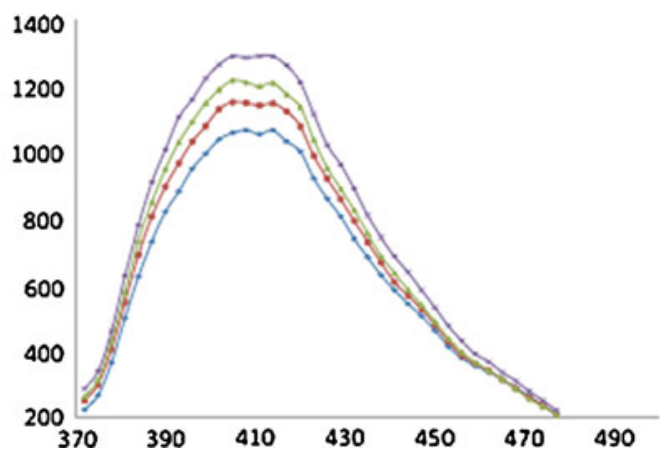

of protein, binding is saturated. The right panel shows the corresponding fluorescence emission spectra but here the intensity changes for each addition of protein showing that binding is not saturated and is therefore weaker. There is no need to record the full spectra, although they are shown here to illustrate the principle. Only the emission at the wavelength of maximum intensity needs to be recorded to avoid bleaching 


\section{Conclusion}

New binder technologies are emerging to supplement antibodies and small organic molecules as binders for proteins in bioanalytical and biomedicinal applications. Most often engineered antibodies and proteins or organic molecules with molecular weights larger than $500 \mathrm{D}$ are considered. The advantages of biomolecules in protein recognition are the many hydrophobic groups, hydrogen bonds, and charge-charge interactions that can be used to form bonds to the analyte and the preorganization of structures that reduce entropy related to binding. Also, the access to efficient development strategies is an advantage, although the time to robust, specific, high-affinity binders is often long. The advantages of small organic molecules are the preorganization of hydrogen bond donors and acceptors that favour binding for reasons of entropy. In addition, synthetic organic chemistry can be used for systematic modification of structure. However, the efforts needed to develop small molecule binders with high affinity and specificity are substantial. Binders that take advantage of both of these molecular aspects have great potential in binder development. So far, only a few examples have been reported based on the polypeptide conjugate technology, in comparison with the large numbers of antibodies and small organic molecules already in use. Nevertheless, the technology reviewed here and others are emerging to address the pressing needs of the pharmaceutical and diagnostic industries as the healthcare system remains the most important endeavour in biotechnology. The binder molecule concept has been proven to have great potential in that perspective. Other technologies beyond those based on monoclonal antibodies and small organic molecules are likely to follow.

Acknowledgements Financial support from the European Commission through the IP CARE-MAN, contract no NMP4-CT-2006-017333, and from the Swedish Research Council (VR) is gratefully acknowledged.

Open Access This article is distributed under the terms of the Creative Commons Attribution Noncommercial License which permits any noncommercial use, distribution, and reproduction in any medium, provided the original author(s) and source are credited.

\section{References}

1. Borrebaeck CAK (2000) Antibodies in diagnostics - from immunoassays to protein chips. Immunol Today 21:379-382

2. Dübel S (2007) Handbook of Therapeutic Antibodies. Wiley-VCH, Weinheim

3. Huston JS, George AJ (2001) Engineered antibodies take center stage. Hum Antibodies 10:127-142

4. Hagemeyer CE, von Zur MC, von Elverfeldt D, Peter K (2009) Single-chain antibodies as diagnostic tools and therapeutic agents. Thromb Haemost 101:1012-1019
5. Stumpp MT, Amstutz P (2007) DARPins: a true alternative to antibodies. Curr Opin Drug Discov Dev 10:153-159

6. Feldwisch J, Tolmachev V, Lendel C, Herne N, Sjöberg A, Larsson B, Rosik D, Lindqvist E, Fant G, Höjden-Guthenberg I, Galli J, Jonasson P, Abrahmsen L (2010) Design of an optimized scaffold for affibody molecules. J Mol Biol 398:232247

7. Schönfeld D, Matschiner G, Chatwell L, Trentmann S, Gille H, Hulsmeyer M, Brown N, Kaye PM, Schlehuber S, Hohlbaum AM, Skerra A (2009) An engineered lipocalin specific for CTLA-4 reveals a combining site with structural and conformational features similar to antibodies. Proc Natl Acad Sci USA 106:8198-8203

8. Bunka DHJ, Stockley PG (2006) Aptamers come of age - at last. Nat Rev Microbiol 4:588-596

9. Lipinski CA, Lombardo F, Dominy BW, Feeney PJ (1997) Experimental and Computational Approaches to Estimate Solubility and Permeability in Drug Discovery and Development Settings. Adv Drug Deliv Rev 23:3-25

10. Driggers EM, Hale SP, Lee J, Terrett NK (2008) The exploration of macrocycles for drug discovery - an underexploited structural class. Nat Rev Drug Discov 7:608-624

11. Hruby VJ (2002) Designing peptide receptor agonists and antagonists. Nature Rev Drug Disc 1:847-858

12. Tegler LT, Nonglaton G, Büttner F, Caldwell K, Christopeit T, Danielson UH, Fromell K, Gossas T, Larsson A, Longati P, Norberg T, Ramapanicker R, Rydberg J, Baltzer L (2011) Powerful protein binders from designed polypeptides and small organic molecules-a general concept for protein recognition. Angew Chem Int Ed 50:1823-1827

13. Baltzer L (2007) Polypeptide conjugate binders for protein recognition. Top Curr Chem 277:89-106

14. Tegler LT, Fromell K, Jonsson B-H, Viljanen J, Winander C, Carlsson J, Baltzer L (2011) Polypeptide conjugate binders that discriminate between two isoforms of human Carbonic Anhydrase in human blood. Chembiochem 12:559-566

15. Andersson T, Lundquist M, Dolphin GT, Enander K, Jonsson B-H, Nilsson JW, Baltzer L (2005) Cooperative binding of human Carbonic Anhydrase II by functionalized folded polypeptide receptors. Chem Biol 12:1245-1252

16. Fersht A (1999) A Guide to Enzyme Catalysis and Protein Folding, W. H. Freeman and Company, New York, chap 11

17. Olofsson S, Johansson G, Baltzer L (1995) Design, Synthesis and Solution Structure of a Helix-Loop-Helix Dimer-a Template for the Rational Design of Catalytically Active Polypeptides. J Chem Soc Perkin Trans 2:21047-2056

18. Baltzer L, Nilsson H, Nilsson J (2001) De novo design of proteins - What are the rules? Chem Rev 101:3153-3163

19. Dunker AK, Silman I, Uversky VN, Sussman JL (2008) Function and structure of inherently disordered proteins. Curr Opin Struct Biol 18:756-764

20. Hajduk PJ (2006) SAR by NMR: putting the pieces together. Mol Interv 6:266-272

21. Dalvit C, Fasolini M, Flocco M, Knapp S, Pevarello P, Veronesi M (2002) NMR-Based Screening with Competition Water-Ligand Observed via Gradient Spectroscopy Experiments: Detection of High-Affinity Ligands. J Med Chem 45:2610-2614

22. Gold L (2001) mRNA display: Diversity matters during in vitro selection. Proc Nat Acad Sci USA 98:4825-4826

23. Smith GP, Petrenko VA (1997) Phage Display. Chem Rev 97:391-410

24. Laudano AP, Doolittle RF (1980) Studies on synthetic peptides that bind to fibrinogen and prevent fibrin polymerization. Structural requirements, number of binding sites, and species differences. Biochemistry 19:1013-1019

25. Enander K, Dolphin GT, Andersson LK, Lundström I, Liedberg B, Baltzer L (2002) Designed, folded polypeptide scaffolds that 
combine key biosensing events of recognition and reporting. J Org Chem 67:3120-3123

26. Enander K, Dolphin GT, Baltzer L (2004) Designed, functionalized helix-loop-helix motifs that bind human Carbonic Anhydrase II - a new class of synthetic receptor molecules. J Am Chem Soc 126:4464-4465

27. Enander K, Dolphin GT, Liedberg B, Lundström I, Baltzer L (2004) A versatile polypeptide platform for integrated recognition and reporting - affinity arrays for protein-ligand interaction analysis. Chem Eur J 10:2375-2385

28. Westhuyzen J, Healy H (2000) Biology and relevance of C-reactive protein in cardiovascular and renal disease. Ann Clin Lab Sci 30:133-143

29. Verma S, Szmitko PE, Ridker PM (2005) C-reactive protein comes of age. Nat Clin Pract Cardiovasc Med 2:29-36

30. Thompson D, Pepys MB, Wood SP (1999) The physiological structure of human C-reactive protein and its complex with phosphocholine. Structure 7:169-177

31. Christopeit T, Gossas T, Danielson UH (2009) Characterization of $\mathrm{Ca} 2+$ and phosphocholine interactions with $\mathrm{C}$-reactive protein. Anal Biochem 391:39-44

32. Renauld RC, Xuereb H (2003) Vision impairment therapies. Nat Rev Drug Discov 2:425-426

33. Parkkila S, Lasota J, Fletcher JA, Ou W, Kivelä AJ, Nuorva K, Parkkila A-K, Ollikainen J, Sly WS, Waheed A, Pastorekova S, Pastorek J, Isola J, Miettinen M (2010) Carbonic anhydrase II. A novel biomarker for gastrointestinal stromal tumors. Mod Path 23:743-750

34. Taylor PW, King RW, Burgen ASV (1970) Kinetics of complex formation between human carbonic anhydrases and aromatic sulfonamides. Biochemistry 9:2638-2645

35. Krebs HA (1948) Inhibition of carbonic anhydrase by sulphonamides. Biochem J 43:525-528

36. Winum J-Y, Vullo D, Casini A, Montero J-L, Scozzafava A, Supuran CT (2003) Carbonic Anhydrase Inhibitors. Inhibition of Cytosolic Isozymes I and II and Transmembrane, Tumor-Associated Isozyme IX with Sulfamates Including EMATE Also Acting as Steroid Sulfatase Inhibitors. J Med Chem 46:2197-2204

37. Jeckling MC, Schauer S, Dumelin CE, Zenobi R (2009) Label-free determination of protein-ligand binding constants using mass spectrometry and validation using surface plasmon resonance and isothermal titration calorimetry. J Mol Recog 22:319-329

38. Holdenrieder S, von Pawel J, Duell T, Feldmann K, Raith H, Schollen A, Nagel D, Stieber P (2010) Clinical Relevance of Thymidine Kinase for the Diagnosis, Therapy Monitoring and Prognosis of Non-operable Lung Cancer. Anticancer Res 30:1855-1862
39. Adam SS, Key NS, Greenberg CS (2009) D-dimer antigen: current concepts and future prospects. Blood 113:2878-2887

40. Ramapanicker R, Sun X, Viljanen J, Baltzer L (2011) Boosting the affinity of a tetrapeptide by polypeptide conjugation in the molecular recognition of the D-dimer. submitted for publication

41. Marks F (1996) Protein Phosphorylation. Wiley-VCH, New York

42. Ślósarczyk AT, Baltzer L (2011) The molecular recognition of phosphorylated proteins by designed polypeptides conjugated to a small molecule that binds phosphate. Submitted for publication

43. Mangalum A, Smith RC (2009) Label-free determination of protein-ligand binding constants using mass spectrometry and validation using surface plasmon resonance and isothermal titration calorimetry. Tetrahedron 65:4298-4303

44. Fromell K, Hulting G, Ilichev A, Larsson A, Caldwell KC (2007) Particulate platform for bioluminescent immunosensing. Anal Chem 79:8601-8607

45. Fromell K, Karlsson M, Forsberg P, Nikolajeff F, Baltzer L (2011) Designed protein binders in combination with nano crystalline diamond for use in high-sensitivity biosensors. Submitted for publication

46. Leung W, Chan CPY, Leung M, Lehmann K, Renneberg I, Lehmann M, Hempel A, Glatz JFC, Renneberg R (2005) Novel „digital-style“ rapid test simultaneously detecting heart attack and predicting cardiovascular disease risk. Anal Lett 38:423-439

47. Aili D, Selegard R, Baltzer L, Enander K, Liedberg B (2009) Colorimetric Protein Sensing by Controlled Assembly of Gold Nanoparticles Functionalized with Synthetic Receptors. Small $5: 2445-2452$

48. Schmitt HM, Brecht A, Piehler J, Gauglitz G (1997) An integrated system for optical biomolecular interaction analysis. Elsevier Advanced Technology, 809-816

49. Albrecht C, Fechner P, Honcharenko D, Baltzer L, Gauglitz G (2010) A new assay design for clinical diagnostics based on alternative recognition elements. Biosens Bioelectron 25:23022308

50. Zhang Q, Norberg T, Bergquist J, Baltzer L (2010) Synthesis of C-11 linked active ester derivatives of vitamin D-3 and their conjugations to 42-residue helix loop helix peptides. Tetrahedron 19:4577-4586

51. Seebach D, Overhand M, Kühnle FNM, Martinoni B, Oberer L, Hommel U, Widmer H (1996) $\beta$-Peptides: Synthesis by Arndt-Eistert homologation with concomitant peptide coupling. Structure determination by NMR and CD spectroscopy and by $\mathrm{X}$-ray crystallography. Helical secondary structure of a $\beta$ hexapeptide in solution and its stability towards pepsin. Helv Chim Acta 79:913-941 